\title{
EFFECT OF ALUMINUM DROSS AND RICE HUSK ASH ON THERMAL AND MOULDING PROPERTIES OF SILICA SAND
}

\author{
E. F. Ochulor ${ }^{1, *}$, M. O. H Amuda², S. O. Adeosun ${ }^{3}$, and S. A. Balogun ${ }^{4}$ \\ 1,2,3 Department of Metallurgical and Materials EngineERing, University of Lagos. Lagos State, NigERIA.

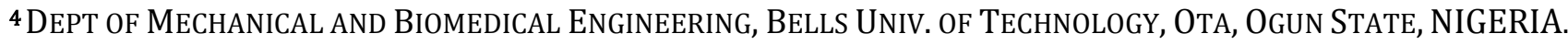 \\ E-mail addresses:1 fochulor@yahoo.com, ${ }^{2}$ mamuda@unilag.edu.ng, 3 samsonoluropo@yahoo.com, \\ 4sanmbo2003@yahoo.co.uk
}

\begin{abstract}
Moulding properties of foundry sand should be controlled so as to minimize casting defects. Its thermal characteristics are vital in defining the solidification kinetics of a cast part, evolving microstructure and mechanical properties. Modification of the thermal properties of the moulding sand mix is important in achieving desired structure and mechanical properties in the cast component. This study investigates the incorporation of 2-12 wt. \% aluminium dross (AIDr) and 1-6 wt. \% rice husk ash (RHA) in silica sand on moulding and thermal properties of the resulting sand mix. Results show that RHA significantly reduced thermal conductivity of the moulding sand from 1.631-1.141 W/m. K (a 30\% reduction).However, AlDr increased its thermal conductivity from 1.631-1.787 W/m.K for 1-6 wt. \% AlDr, which later dropped progressively from 1.753-1.540 W/m.K for 8-12 wt. \%. The moisture content increased abruptly from 4.0-4.2\% for 6-8 wt. \% AIDr addition but decreased from 4.0-2.8\% for0-6 wt. \% RHA addition in the moulding sand mix.
\end{abstract}

Keywords: Aluminum dross (AIDr), rice husk ash (RHA), silica sand, moulding properties, thermal properties, sand mix.

\section{INTRODUCTION}

Silica sand is a good foundry material for casting of both ferrous and non-ferrous alloys due to its availability and high refractoriness. It can absorb and transmit heat and has sufficient permeability to allow gases generated during casting to pass between the particles without causing defects. Foundry sand is made within strict particle size distribution to tailor the properties of the materials to the intended casting process [1]. These benefits by sand casting have not been fully explored in the casting of thin wall parts. Thin wall casting technology is currently important due to the stringent energy requirements in the automotive industry. The reasons for this low utilization of sand casting can be traced to problems faced by foundry industries in developing countries. These problems are operational and technical in nature [2]. Solving the needed problem would be an incentive to the development of the foundry industry [3].

Formulation of moulding sand mix is targeted at good moulding properties and other specific properties desired in the microstructure of the final cast product. Moulding sand additives that are generally added to the moulding mixture to develop some special property in the sand include coal dust, dextrin and wood floor. In thin wall casting technology where reduction in heat loss of the cast part is required in order to reduce cooling rate, additives are incorporated into the moulding sand so as to reduce its thermal conductivity.

The authors of [4] investigated the effect of silica sand prepared by addition of varying percentages of iron fillings on the microstructure and properties of gray iron. The iron fillings served to vary the heat storage capacity (HSC) of the mould material and had significant effect on the as-cast gray iron mechanical properties. The author in [5] studied the effects of varying the corn cob and rice husk ash on the properties of moulding sand and observed that the additives improved dry strength of the moulding sand. However, there was decrease in green strength, moisture content and permeability of the resulting sand mix. The authors in [6] noticed a decrease in moisture content in their study of adoption of rice husk ash as an aggregate in foundry sand mould production. The authors in [7] investigated the effect of moulding sand-aluminum dross mix on the microstructure and mechanical properties of as -cast thin wall ductile iron (TWDI) and concluded that microstructure, hardness and tensile strength of TWDI samples were impaired, while ductility of these samples were enhanced when compared to the control samples 
cast without the aluminum dross mould additive. To date, most methods used to produce thin wall castings focus on metal chemistry, inoculation and gating practice. Few practical methods have been developed to control cooling and the reduction of solidification rates in convectional sand moulds. However, improvement in the heat capacity and thermal conductivity of the mould and core materials may have the potential to reduce casting wall thickness more than all the other factors combined. By adjusting the density and thermal properties of individual mould and core components or inserts, the mould/core package can be engineered to give optimum flow and cooling characteristics [8].

In this research, aluminum dross (AlDr) and rice husk ash (RHA) are used as the moulding sand additives. Aluminum dross is a by-product of secondary aluminum smelting, comprising of a mixture of metallic aluminum and non-metallic part, mostly aluminum oxide. Disposal of this product from aluminum smelters and foundries has continually posed a challenge, hence the need to determine their suitability as an additive in terms of moulding and thermal characteristics of the final moulding sand mix. Rice husk Ash (RHA) is produced by the combustion of rice husk, which is a by-product of rice milling industries. Rice husk is an agro-waste, its disposal also constitutes environmental health hazard.

The thermal properties of importance in this work are thermal conductivity (inverse of thermal resistivity) and heat/ thermal diffusivity.

Thermal Conductivity: Moulds with high thermal conductivity remove heat faster from the molten metal, causing it to solidify earlier and stop flowing.

Heat Diffusivity: Moulds with high heat diffusivity transfer heat faster from the molten metal, causing it to freeze earlier and stop flowing. The heat diffusivity relation is represented in Equation (1).

$$
\text { Heat / Thermal diffusivity }=\frac{K m}{\rho C m}
$$

In (1), $\mathrm{Km}(\mathrm{W} / \mathrm{m} \cdot \mathrm{K})$ is thermal conductivity, $\rho\left(\mathrm{kg} / \mathrm{m}^{3}\right)$ is density and $\mathrm{Cm}(\mathrm{J} / \mathrm{kg} \cdot \mathrm{K})$ is specific heat capacity of the mould material.

This study is aimed at producing a moulding sand mix with thermal properties such as low heat capacity, thermal conductivity and diffusivity with adequate moulding properties. This sand mix would allow reduction in cooling rate, which is desired to achieve thickness reduction with potential for use in casting of thin and super thin - wall parts for light weight automotive application.

\section{MATERIALS AND METHODS}

\subsection{Materials}

The materials used for this work are silica sand obtained from Epe, Lagos State and aluminum dross obtained from Aluminum Rolling Mills, Ota, Nigeria with its chemical composition shown in Table 1. Rice husk an agro-waste which is a by-product of rice milling was obtained from Ifo in Ogun State, Nigeria and its chemical analysis is shown in Table 2.

\subsection{Methods}

Combustion of $50 \mathrm{~kg}$ of rice husk was carried out in a Gemco CFR 90337 electric furnace at $700^{\circ} \mathrm{C}$, in the Foundry Shop of Federal Institute of Industrial Research (FIIRO), Oshodi, Lagos, Nigeria.

Sieve analysis was carried out on the silica sand, aluminum dross and rice husk as hand only particles sizes of $250-300 \mu \mathrm{m}$ were used for moulding sand preparation. This is important as this particle size range is that specified for moulding sand preparation used by the quality control laboratory of Nigerian Foundries Limited, Lagos, Nigeria, where the study was conducted. Using the standard composition of moulding sand as in Table 3, six different compositions of the moulds were prepared by adding varying weight percentages of AlDr and RHA to the moulding sand as in Tables 4 and 5 respectively.

The sand constituents were mixed using a Rhino model IRM-500 sand mixer with a mixing time of 5 minutes. It is important to note that the choice of the weight percentages of the additives used was based on a preliminary trial test conducted on $600 \mathrm{~g}$ of moulding sand in the Quality Control Laboratory of Nigerian Foundries Limited. The result helped in the determination of the upper limit (at $12 \mathrm{wt}$. \% Al dross and 6 wt. \% RHA) that were used, as higher weight percent produced negative effect on the moulding sand properties based on the moulding sand property test conducted.

Table 1: Chemical Composition of Aluminium Dross

(Quality Control Department of Aluminium Rolling Mills, Ota, Ogun State Nigeria)

\begin{tabular}{lllllllllll}
\hline Const. & $\mathrm{Al}_{2} \mathrm{O}_{3}$ & $\mathrm{SiO}_{2}$ & $\mathrm{MgO}$ & $\mathrm{NaO}$ & $\mathrm{K}_{2} \mathrm{O}$ & $\mathrm{CaO}$ & $\mathrm{Fe}_{2} \mathrm{O}_{3}$ & Sulphate & Chloride & $\mathrm{Al}$ \\
\hline Wt. \% in $\mathrm{AlDr}$ & 43.38 & 3.12 & 0.12 & 9.84 & 0.72 & 1.57 & 0.70 & 0.60 & 1.98 & 37.97 \\
\hline
\end{tabular}

Table 2: Chemical Composition of Rice Husk Ash

\begin{tabular}{llllllllll}
\hline Const. & $\mathrm{SiO}_{2}$ & $\mathrm{Al}_{2} \mathrm{O}_{3}$ & $\mathrm{TiO}_{2}$ & $\mathrm{Fe}_{2} \mathrm{O}_{3}$ & $\mathrm{CaO}$ & $\mathrm{MgO}$ & $\mathrm{K}_{2} \mathrm{O}$ & $\mathrm{Na}_{2} \mathrm{O}$ & LOI \\
\hline Wt. \% in RHA & 93.15 & 0.21 & 0 & 0.21 & 0.41 & 0.45 & 3.21 & 0 & 2.36 \\
\hline
\end{tabular}




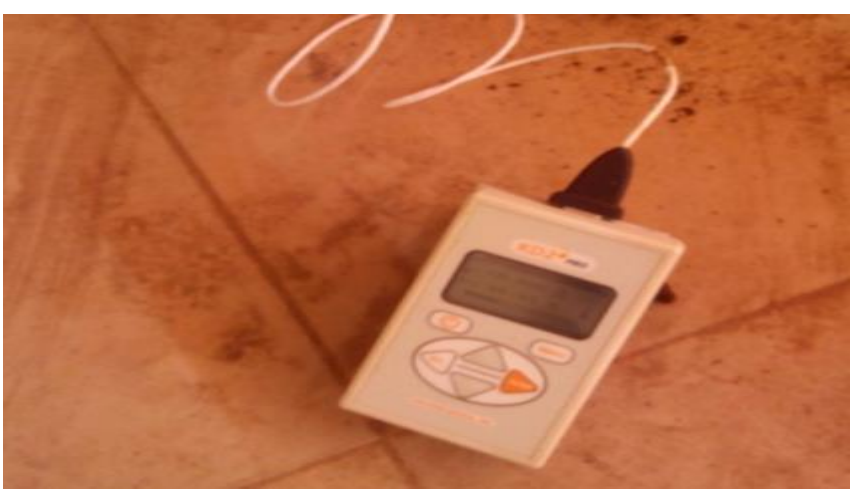

(a)

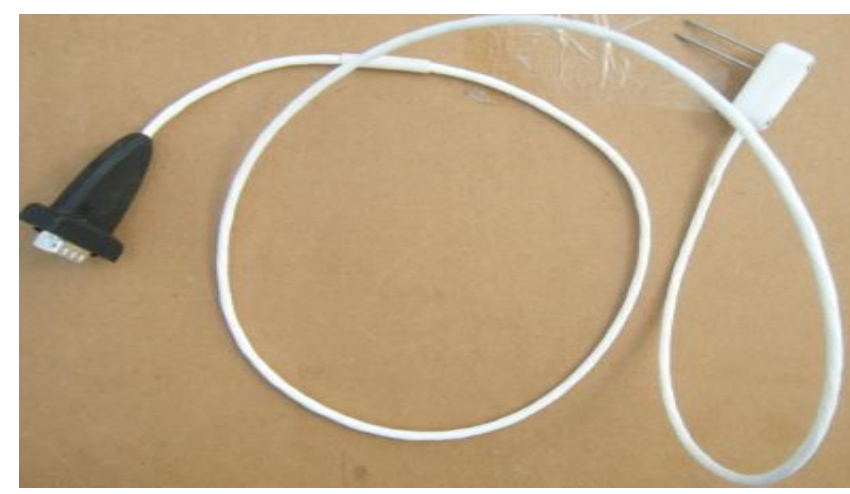

(b)

Figure 1 (a) KD 2 Pro Thermal Conductivity Meter, (b) TR-1 sensor

Table 3: Control Composition of green moulding sand

\begin{tabular}{lll}
\hline S/No & Materials & Wt (\%) \\
\hline 1 & Silica Sand & 96.4 \\
2 & Bentonite & 2.2 \\
3 & Starch & 0.8 \\
4 & Water & 0.4 \\
5 & Coal Dust & 0.2 \\
\hline
\end{tabular}

Table 4: Sand Specimen with wt. \% of Aluminum Dross (AIDr)

\begin{tabular}{cccccccc}
\hline S/No & 1 & 2 & 3 & 4 & 5 & 6 & 7 \\
\hline Specimen & D & D1 & D2 & D3 & D4 & D5 & D6 \\
Wt.\% AlDr & 0 & 2 & 4 & 6 & 8 & 10 & 12 \\
\hline
\end{tabular}

Table 5: Sand Specimen with wt. \% of RHA

\begin{tabular}{cccccccc}
\hline S/No & 1 & 2 & 3 & 4 & 5 & 6 & 7 \\
\hline $\begin{array}{c}\text { Specimen } \\
\text { Wt.\% }\end{array}$ & RH & RH1 & RH2 & RH3 & RH4 & RH5 & RH6 \\
RHA & 0 & 1 & 2 & 3 & 4 & 5 & 6 \\
\hline
\end{tabular}

\subsection{Thermal Property Tests}

The thermal property of importance in this work is thermal conductivity (which is the inverse of Thermal resistivity) and thermal diffusivity. These property of the sand mix were determined using KD 2 Pro Thermal Conductivity Meter (see Figure 1a), during moulding after the pattern is removed (before coupling). The TR-1 sensor (Figure 1b) was used for thermal conductivity assessment. The read temperature is $29^{\circ} \mathrm{C}$.

\subsection{Moulding Sand Tests \\ 2.4.1 Shatter Index}

A shatter index tester was adopted for this test, $50 \mathrm{~mm}$ diameter moulding sand specimen was rammed in a specimen tube and the weight of the sample (150g) was recorded. The specimen was ejected from the specimen tube by placing it on the shatter index tester and the plunger was used to eject the sand by making a free fall onto the anvil squarely in the center. The anvil cap was then removed carefully and the sieve assembly lifted off to allow removal of sieve from pan. The sand in the receiver is weighed and the weight of sand remaining on the sieve is taken. The shatter index was calculated as the percentage of the difference of these two weights.

\subsubsection{Green Sand Strength}

This property was estimated using the Universal Strength Testing machine (electric motor driven). The test sample was a standard cylindrical specimen. The moulding sand was weighed $(150 \mathrm{~g})$ and poured into the specimen tube and rammed to achieve $50 \mathrm{~mm}$ diameter and $50 \mathrm{~mm}$ height. The rammed specimen was removed from the tube and placed in the compression head of the machine, the weight arm was raised slightly and the test specimen inserted between the compression heads and tested by turning the wheel of the tester until the test broke. The value of the green sand strength was then recorded.

\subsubsection{Permeability}

An electric permeability meter was used to determine this property. It was determined by measuring the rate of flow of air through a compacted specimen under standard conditions. The standard cylindrical specimen is prepared and then tested. The permeability was directly measured as the permeability number.

\subsubsection{Moisture Content}

This property was determined by the Ridsdale moisture content teller. $50 \mathrm{~g}$ of green sand was weighed out and placed in a sample pan, and transferred to the bottom of the machine and tested. The instrument was provided with a pressure gauge to read directly the percentage of moisture present in the moulding sand.

\subsubsection{Percent Compactibility}

A fixed volume of loose sand was rammed under standard conditions and the percentage reduction in volume represents the compactibility. 


\section{RESULTS AND DISCUSSION}

3.1 Effect of Aluminium dross (AlDr) Moulding sand Additive on Moulding Properties

The effects of AlDr addition on moulding sand properties for all the sand mixes are shown in Figures 2-6 These display the variation of green shear strength, permeability, percent compactibility, moisture content and shatter index with wt. \% AlDr respectively. The addition of AlDr reduced the green sand strength from $89,82,48 \mathrm{KN} / \mathrm{m}^{2}$ for 0,2 and $12 \mathrm{wt}$. \% AlDr respectively, however, these are still within foundry standards. Permeability increased slightly from $130-162 \mathrm{~cm} / \mathrm{s}$

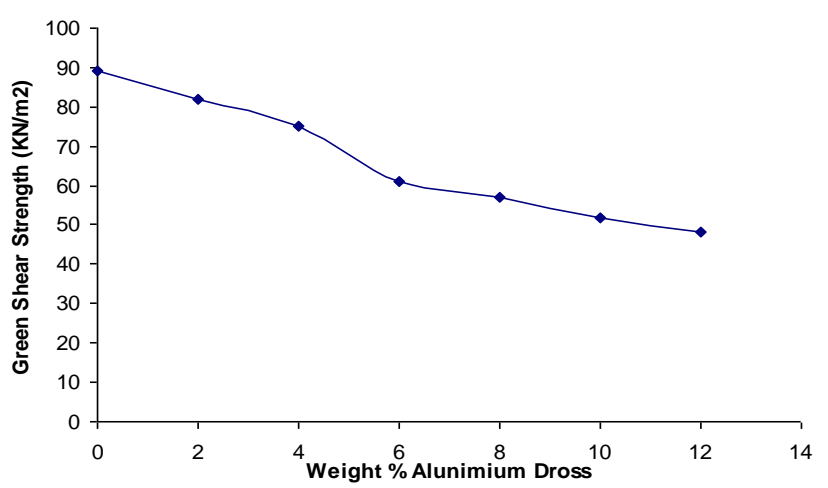

Figure 2: Variation of green shear strength with weight \% AIDr in sand-AIDr mix.

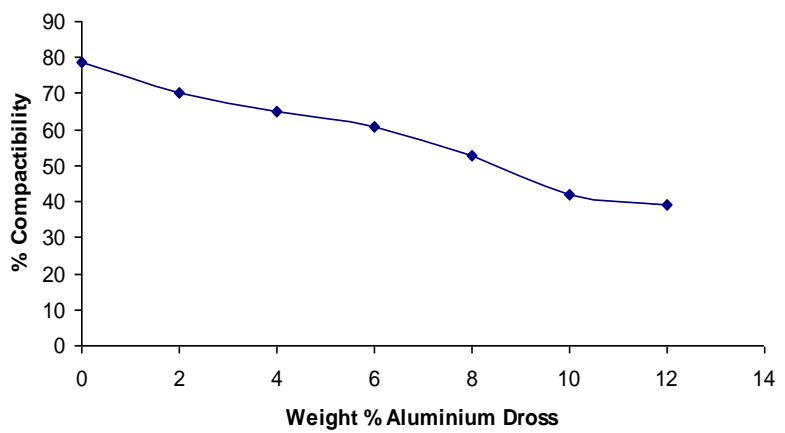

Figure 4: Variation of Percent compactibility with weight \% AIDr in sand-AIDr mix

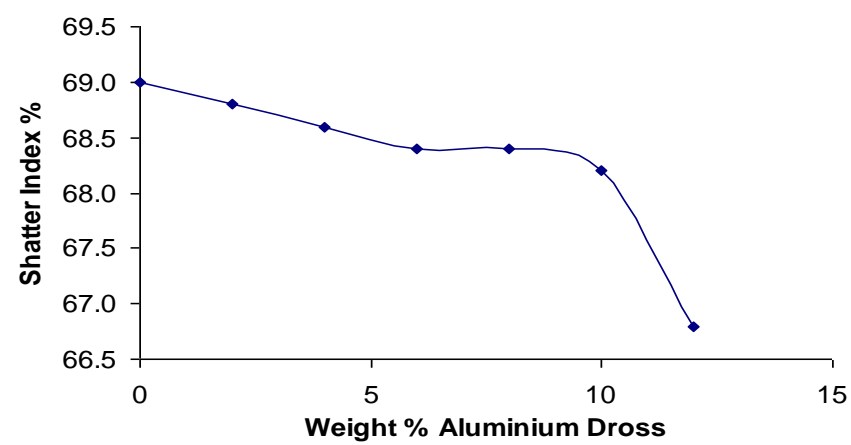

Figure 6: Variation of percent shatter index with we weight weight \% AIDr in sand-AIDr mix from 0-2 wt. \% AlDr and this implies increased pore spaces generated by AlDr addition, which later reduced to $122 \mathrm{~cm} / \mathrm{s}$ at $12 \mathrm{wt}$ \% AlDr. Moisture content increased from 4.0-4.2 \% as AlDr increased from 6- 8 wt. \%. This sharp rise could be attributed to decrease in plasticity of the mix hence the need for more water to create necessary bonding between the moulding mix components. The shatter index property was impaired at 12 wt. \% AlDr and percent compactibilty followed a similar trend.

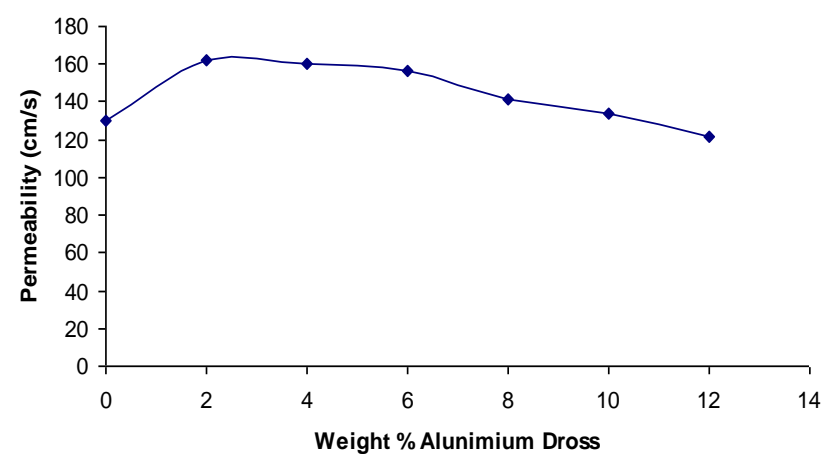

Figure 3: Variation of permeability with weight $\%$ AlDr in sand-AIDr mix

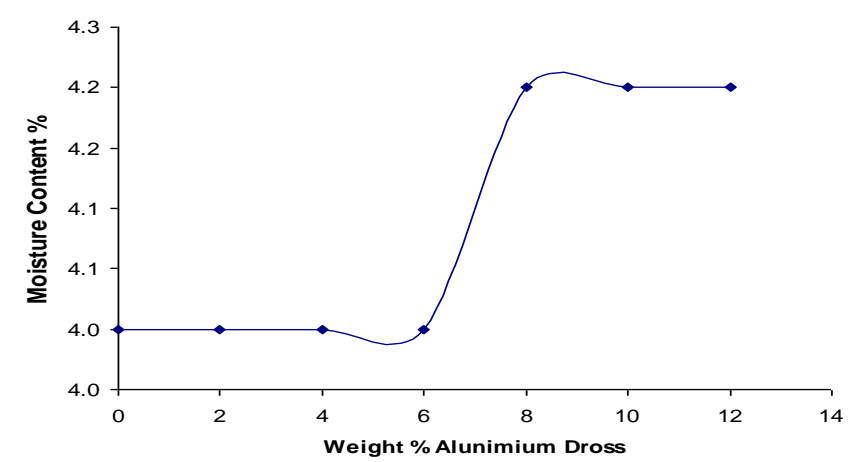

Figure 5: Variation of moisture content with weight $\%$ AIDr in sand-AIDr mix

\subsection{Effect of aluminium dross (AlDr) Moulding sand Additive on Thermal Properties}

The effects of AlDr addition on thermal conductivity and diffusivity of sand mixes are displayed in Figures 7 and 8 respectively. The thermal conductivity of the sand mix shown in Figure 7 increased significantly from that of the control mix up to 6 wt. \% AlDr, after which it dropped progressively with further increase in weight percent of AlDr from 8-12wt. \%. The reduction in thermal conductivity at $6 \mathrm{wt}$. \% AlDr implies that some level of thermal insulation was achieved. This can be attributed to the larger proportion of alumina and silica in the sand mix at 6-12 wt. \% AlDr addition. This implies that when used as moulding sand for casting, delayed solidification of samples will occur. It should be noted that values of 
1.787, 1.753and1.718 W/m.K for 6,8 and 10 wt. $\%$ respectively (except that of $12 \mathrm{wt}$ \% AlDr of 1.540 $\mathrm{W} / \mathrm{m} . \mathrm{K}$ ) are still higher than that of the control sand mix (0 wt. \% AlDr) of $1.631 \mathrm{~W} / \mathrm{m}$. K. The thermal diffusivity, which is a function of thermal conductivity increased only slightly from 2 - $6 \mathrm{wt}$. \% AlDr after which it dropped significantly from 8 - 12 wt. \% AlDr reaching 0.514 $\mathrm{mm}^{2} / \mathrm{s}$ at 12 wt. \% (Figure 8 ).

\subsection{Effect of rice husk ash (RHA) Moulding Sand Additive on Moulding Properties}

Figures 9-13 show the graphs of green shear strength, permeability, \% compactibility, moisture content and

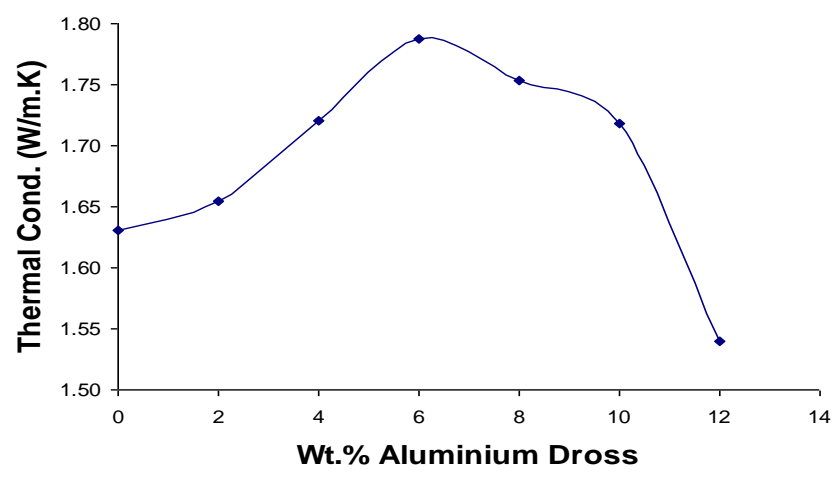

Figure 7: Variation of thermal conductivity with weight \% AIDr in sand-AIDr mix

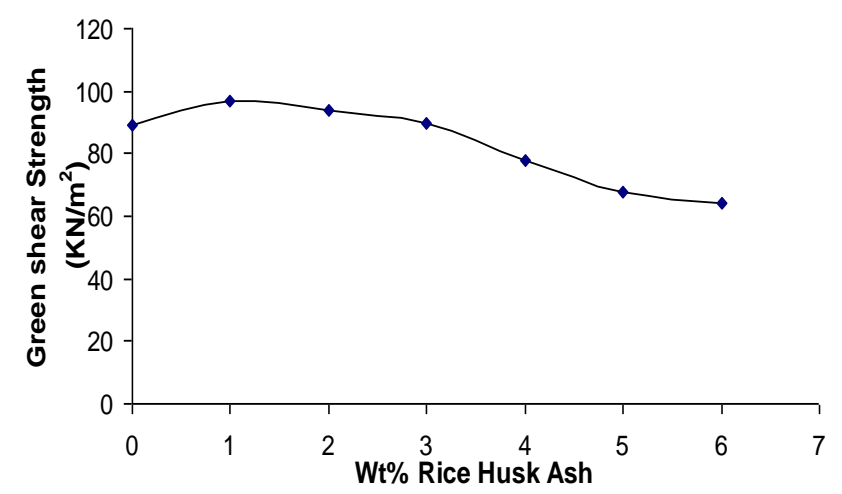

Figure 9: Variation of Green Shear Strength with Weight \% RHA in sand mix

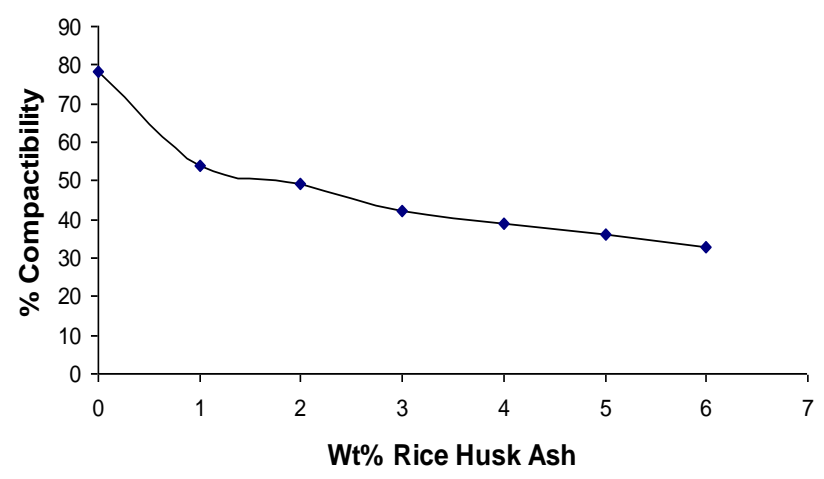

Figure 11: Variation of \% Compactibility with Weight \% RHA in sand mix shatter index with wt. \% RHA respectively. The addition of the RHA additive increased green sand strength initially to $97 \mathrm{KN} / \mathrm{m}^{2}$ for $1 \mathrm{wt} \% \%$ addition but reduced to $64 \mathrm{KN} / \mathrm{m}^{2}$ as RHA addition increased to $6 \mathrm{wt} . \%$. Permeability decreased from $110-60 \mathrm{~cm} / \mathrm{s}$ as the wt. $\%$ of RHA increased from 1- $6 \mathrm{wt}$ \% RHA. This could be attributed to the replacement of the pore spaces in the sand by the RHA, thereby reducing its permeability. Moisture content also reduced from 4.0 - 2.8\% for 0-6 wt. $\%$ RHA addition as the mix increased in plasticity with the addition of rice husk ash. This trend was also noticed by the investigations in [5] and [6]. Percent compactibilty and shatter index followed the same trend.

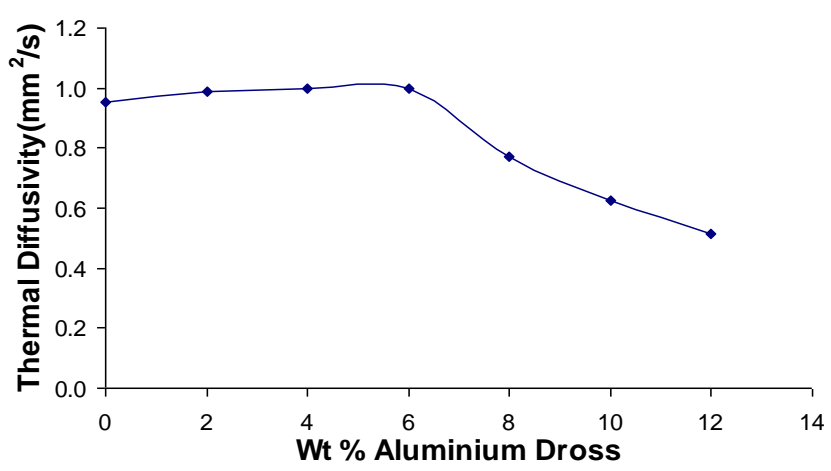

Figure 8: Variation of thermal diffusivity with weight $\%$ AIDr in sand-AIDr mix

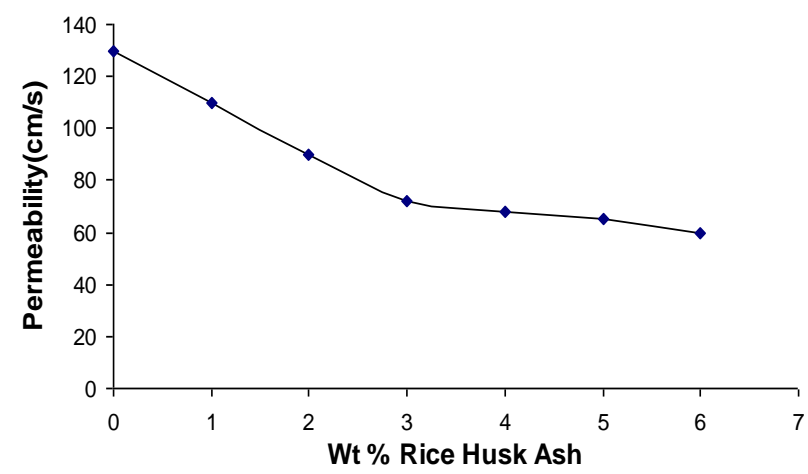

Figure 10: Variation of Permeability with Weight \% RHA in sand mix

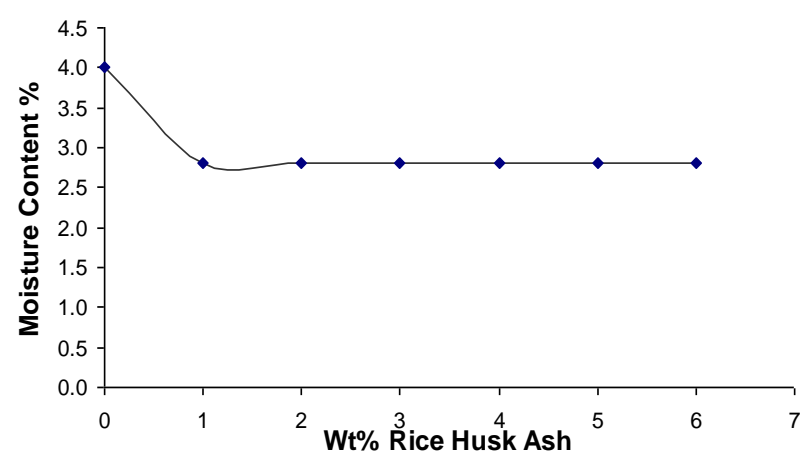

Figure 12: Variation of \% Moisture Content with Weight \% RHA in sand mix 


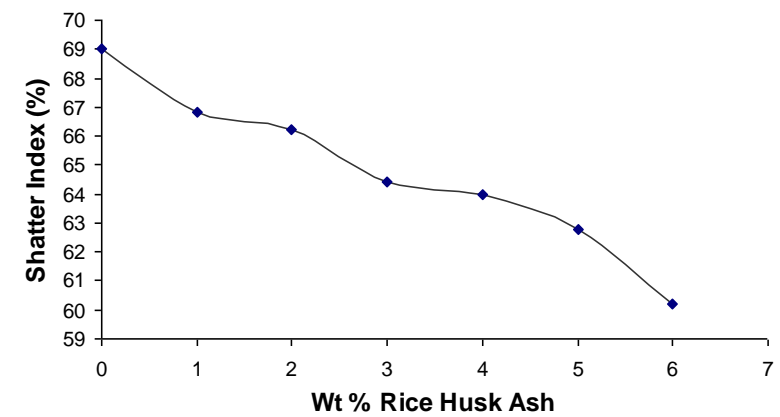

Figure 13: Variation of Shatter Index with Weight. \% of RHA in sand mix

The variation of thermal conductivity and diffusivity of the sand mixes with wt. \% RHA additive is shown in Figures 13 and 14 . The thermal conductivity reduced as wt. \% RHA increased. This indicates that some measure of thermal insulation of the sand mix was achieved. The same trend was observed for the thermal diffusivity plot. Using RHA as additive, thermal conductivity reduces by $30 \%$ as thermal conductivity of control silica sand mix without RHA is $1.631 \mathrm{~W} / \mathrm{m} . \mathrm{K}$ and that with $6 \mathrm{wt} \%$ RHA is 1.141 W/m.K. Showmann and Aufderheide, (2003) noticed similar results using low density alumino-silicate sand (LDASC) as sand additive/replacement in their study on thin wall casting technology.

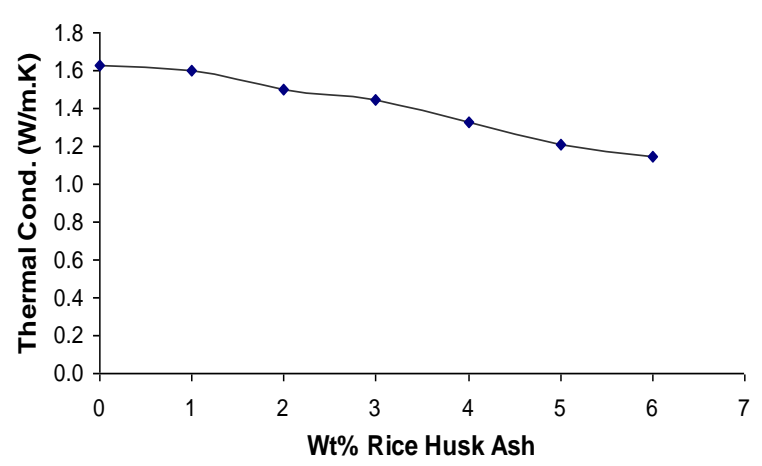

Figure 13: Variation of thermal conductivity with weight $\%$ RHA in sand-RHA mix

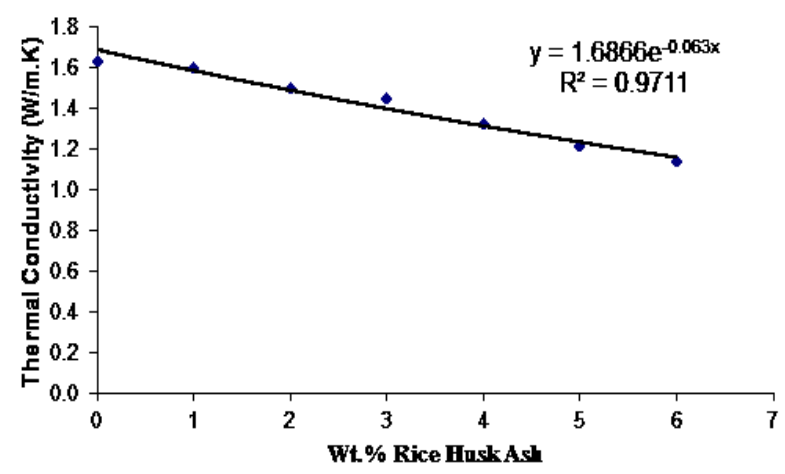

Figure 15: Regression plot for variation of thermal conductivity with weight \% RHA in sand-RHA mix
Regression analysis shows that the relationship follows a downward exponential trend as in Equation 2 and 3 for thermal conductivity and diffusivity respectively. The regression plots are shown in Figures 15 and 16 for thermal conductivity TC and diffusivity TD respectively:

$$
\begin{aligned}
& T C=1.6866 e^{-0.063(W t \% R H A)}=0.9711 \\
& T D=0.7757 e^{-0.0585(W t . \% R H A)}=0.9464
\end{aligned}
$$

\section{CONCLUSION}

This study has shown that aluminium dross and rice husk ash can be incorporated as moulding sand additive depending on the structure desired in the final cast product. AlDr and RHA both lowered the moulding properties of silica sand when used as an additive. However, these properties are still within the range as specified by the quality control Department of Nigerian Foundries Limited, Lagos, Nigeria where the tests were conducted.

A 30\% reduction in thermal conductivity was achieved at 6 wt. \% RHA. This indicates that silica sand-RHA sand mix has viable potential for adoption for thin and super thin wall casting technology where reduction in cooling rate is vital to achieve desired microstructure in the cast part. However, all the silica sand- AlDr mix showed increase in thermal conductivity except for $12 \mathrm{wt}$ \% AlDr mix.

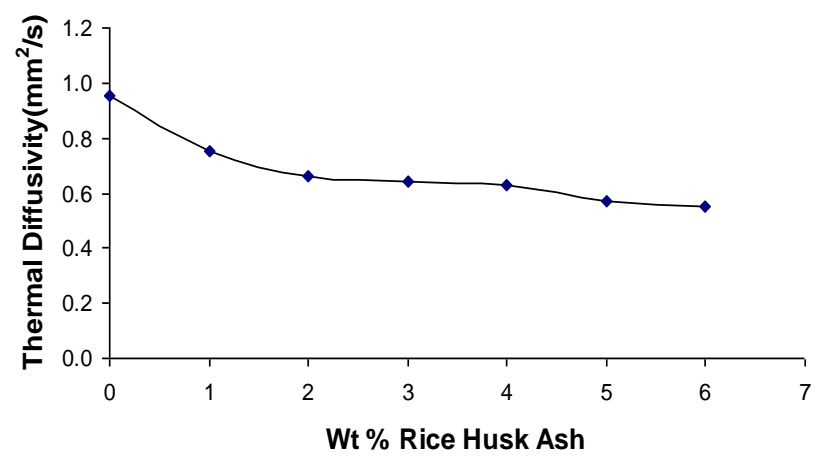

Figure 14: Variation of thermal diffusivity with weight \% RHA in sand-RHA mix

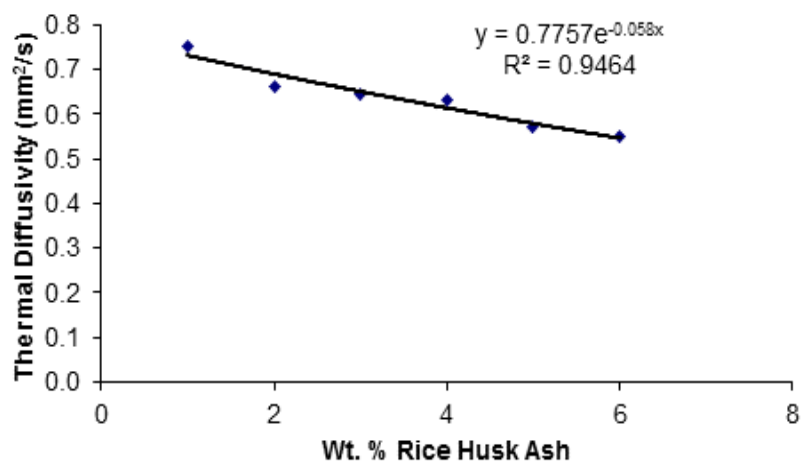

Figure 16: Regression plot for variation of thermal diffusivity with weight \% RHA in sand-RHA mix 


\section{REFERENCES}

[1] Plain P.L Principle of Foundry Technology, McGrawHill publishing Limited, New Delhi.2000

[2] Ibitoye, S. A. and Ilori, M. O. "Indigenous metal casting in Nigeria: its technology, attendant problems, business prospects and policy implication". Technovation, Vol. 18, Number 11, pp705-711, , 1998,

[3] Ibitoye, S. A. "Effect of the addition of sodium silicate and bulk density variation on the permeability of potter's clay- bonded moulding sand". Nigerian Society of Engineers Technical Transactions, Vol. 40, Number2, pp 67-77, 2005

[4] Adedayo, A. V. and Aremo, B. "Influence of mould heat storage capacity on properties of gray iron". Journal of Minerals \& Materials Characterisation \& Engineering, Vol. 10, Number 4, pp 387-396. 2011,
[5] Aribo. S. "Effect of varying corn cob and rice husk ashes on properties of moulding sand" Journal of Minerals \& Materials Characterisation \& Engineering, , Vol. 10, Number 15, pp 1449-1455. 2011,

[6] Aigbodion, V. S; Hassan, S. B; Olajide, S. O; Agunsoye, O. J; Abdulrahaman, A. S; Okafor, G. E; "The use of rice husk ash as an aggregate for foundry sand mould production", Proceedings of the 25th NMS Conference, Nigeria, pp 16-22. 2008.

[7] Ochulor, E. F; Amuda, M. O. H; Adeosun, S. O. and S. A Balogun, S. A. "Mechanical properties of thin wall ductile iron cast $\mathrm{n}$ moulding sand/ aluminium dross mix. The West Indian Journal of Engineering Vol. 39, Number 1, pp 17-24. , 2016.

[8] Showman R. E and Afterheide R. C. "A process for thin wall castings" AFS Transactions 03-145. 2003. 